\title{
The Impact of Net-Migration on Total Fertility Rate in Sub-Sahara African Countries: Empirical Evidence from Nigeria
}

\author{
Muhammed A. Obomeghie (PhD) \\ Idris Abubakar (M.Sc) \\ Yerima Isah Abdulrahman(M.SC) \\ Auchi Polytechnic, Auchi.Edo State, Nigeria
}

Doi: 10.19044/esj.2018.v14n11p34 URL:http://dx.doi.org/10.19044/esj.2018.v14n11p34

\begin{abstract}
The aim of the study is to empirically analyse the impact of netmigration on total fertility rate in Sub-Sahara African countries using data from Nigeria. The rational for the study is under-scored by the need for SubSahara African Countries to have a balanced fertility rate that will enable them to achieve their desired economic growth and development, a situation which their current fertility rate cannot sustain; partly due to the migration activities of its working population. Secondary time series data on targeted variable covering the period from 2000 to 2016 were collected and analysed using econometric packages. Findings show that net-migration impact on total fertility rate positively in Nigeria. It is recommended that government should evolve and maintain a balance migration policy that will help to reduce the current high fertility rate through a cultural re-orientation of Nigeria communities which still places preference on large families.
\end{abstract}

Keyword: Total fertility, food security, climate change, and net-migration

\section{Introduction}

Scholars in various fields such as Epidemiologist, Sociologist, Demographers, Statisticians et cetera have often sought answer to the question of what determines total fertility rate in different societies. While some argue that total fertility is determined by access to education, access to health care and level of income, others argue that the stage a country finds itself in the demographic transition determines the level of total fertility in that country (Kalwa, 2010; Angeles, Guyikey and Mroz, 2005 and Madhavan, 2001). It should be poited out that different societies face different fertility determinants depending on its stage of demographic transition coupled with the prevailing cultural affinity of that society. For example, a society that prefers male 
children to female children may find itself facing a high total fertility rate. In such case even if a married couple has many female children, the desire to have a male child will continue to push her total fertility rate (Dubta and Dubey, 2001).

Empirical findings with respect to factors determining total fertility of any country have shown mixed results. While fertility rate of some countries have been found to be a function of the prevailing population policies (Desta, 2014). Others have found that access to education and health information such as the use of contraceptives are the main determinants (Currais, 2000). Studies such as the work of McNicoll, (1997) have argued that the demographic transition stage of the country determines the total fertility rate of the country at that moment.

Equally the studies of Wiel, (2013) noted that the level of economic growth in a country have a considerable effect on the total fertility rate of that country especially in a situation where the society is an agrarian society. Shultz (2005) on his part noted that the state and level of health care facilities and other health infrastructure availability also contribute to the total fertility rate of the society.

Form the foregoing one may perceive that the rate and level of migration have different effects on both the advanced countries (the migrant receiving countries $\mathrm{MRC}$ ) as well as the less developed countries (the migrant sending countries MSC which most Sub-Sahara African Countries represent).

Despite various attempts by experts in exploring the relationship between migration and fertility, the interaction between the two variables have been relatively under-explored and under - theorized. This is due to the fact that most migration and fertility relationship has been conducted for the United States and Western European countries. Other studies on fertility rate have been mostly undertaken along household economic decision- making especially in cases where the analysis has been decomposed into rural and urban households, economically stable and non-economically stable regions within a country etc. This has given very little explanation of what obtains at the country-wide level.

As well, some researchers have focused on the individual action of migrants in the destination countries of such migrants without adequately capturing the result of the combined distorted activities of emigrants from the home country hence, this study contends that the appropriate measure of current total fertility rate of a country with respect to migration should be the use of the county's net-migration statistics, this is because some countries, especially Sub-Sahara African Countries engage more in sending migrants to the advance countries (MRC) consequently, net-migration in both MSC and MRC differs with respect to its impact on total fertility rate. While in MRC the total fertility level may be increased slightly. On the other hand, fertility 
may decrease, increase or net-neutral in the MSC depending on other factors like the culture and tradition of the people which may cloud-out other effect of net-migration at that point in time.

The researchers of this work noted further that most studies on migration and fertility have failed to use aggregate time series data on national level for Sub-Sahara African countries who are the major suppliers of migrants to other regions of the world. Based on the above realization, this study adopts empirical data from Nigeria to determine the impact of net - migration on total fertility rate in Sub-Sahara African Countries.

A study of this magnitude has become profound because there is the believe that when Sub-Sahara African youths travel abroad mostly for economic reasons, the funds they remit back home helps to either push the fertility rate upwards (back home) due to more access to funds that is used for child-bearing and other economic activities. Migrants also transfer the notion of low fertility which they have acquired from their host western countries back home. However net-migration may be neutral to total fertility rate in Sub Sahara African because the prevailing culture must be preserved. Given the above scenario, this study is significant to the migrant sending countries, the migrants receiving countries as well as other governmental and nongovernmental bodies that are stakeholders in migration, fertility analysis and policy making.

The relationship between migration and total fertility among SubSahara African countries can be seen as independent outcome based on related variables of the same cause such as poverty, economic deprivation etc, because evidences have shown compelling relationships between both variables. Studies such as Lindstrom and Saucedo (2002) and Singley and Landale (1998) investigated the relationship between fertility and migration for the case of people migrating from countries with high fertility to country with low fertility. They concluded in some parts that migration is a disruptive process for fertility because migrants tends to postpone having children because of the psychological and social demands associated with living in a new environment as well as separating from their spouses. A separate research by Bradatan (2005) confirmed the fact that migrants are a selected part of the population with special characteristics that tend to already behave like people in the host countries in terms of child bearing.

By net-migration we are referring to international migration for the purpose of this study.

Goldstein (1976) noted that migration has remained a step-child in demography despite its recognized importance. He noted further that this may either be as a result of paucity of accurate international migration data or the sources of calculating net- migration rates are not complete even when they exist unlike those for birth and death rates. 
Slebos (2003) observed that while migration rates have increased, fertility rates have declined in both MRS and MRC. In fact, he concluded that in most developed countries such as OECD countries, fertility rates have declined to levels below those needed to secure generational replacement even though the OECD countries are accepting migrants from high fertility countries such as Sub-Sahara African countries.

According to Liu (1975) net-migration rate is the difference between the number of immigrants (people coming into an area) and the number of emigrants (people leaving the area) throughout the year. Some researchers have also given a distinction between the attitudes of internal and international migrants with respect to fertility while others think otherwise (Hamear and Tomas (1997). Ebank, et al (1975) conducted a study on the influence of emigration on fertility in Barbados and they found that emigration was pivotal to fertility decline of the nation.

According to Sklar (1974) cited in Bradatan (2005), while researching with central European scenario, observed that massive emigration of young men in the 1900s made it increasingly difficult for women in Czeck, Baltic and Polish areas to find husbands and as a result, age at marriage and number of single women increased. This led to a drastic fall in fertility in those migrant sending countries.

Agadjanian, Yabiku and Can (2012), introduced the concept of successful and less-successful migrants. They believe migrants' success is defined by the amount of remittance they send back to their family. They believe that successful migrants often come back home, which is largely associated with keeping up with the tradition and culture of their societies (fertility inclusive). To them fertility in this case may remain high while for less successful migrants who hardly come home, a break in culture and tradition (fertility inclusive) occurs and this mostly results in lower fertility. We should bear in mind that most immigration activities generates equal emigration in the opposite direction. However, one must also note that immigrants are mostly younger than emigrants hence we should expect some distortion in fertility rate in both.

According to Murphy (2016), the impact of migration on population growth is more complex than simply net - migration because immigrants also contribute to birth and death in the population and emigrants removes their births and deaths from the population.

Fargues (2007) argues that migrants adopts and transmit fertility ideas of their host countries back home, therefore countries with large migrants should expect to have a convergence of fertility rates between the home country and the destination country of such migrants. However, he noted that there is going to be a difference in each home country because migrants select different destination as their host countries. 
Beine, et al (2008), studied the link between international migrant and fertility by focusing on the impact of norms from the host country total fertility rates. They found a strong evidence of transfer of fertility norms from migrants to their host countries.

According to Caldwell, (1982) and Kuliu, (2005) there are four main theoretical perspectives for explaining migration and fertility behavior. They are Socialization, Adaptation, Selectivity and Disruptive perspective.

Elaborating further, Kahn (1988), Stephen and Bean, (1992) pointed out that the socialization theory predicts that there is no significant change in the fertility of migrants compared to that of stayers at home irrespective of the duration of stay abroad because childhood socialization is what matters in fertility behavior. However, some findings have shown that the first generation of migrants maintains the fertility behavior of migrant sending country (MSC) while the second generation exhibits the fertility pertarn of the migrant receiving country (MRC).

The adaptation theory considers the context into which the migrant is arriving as most influential, stating that migrants will exhibit fertility rates similar to non-migrants at destination. According to Ribe and Schultz (1980), the adaptation theory assumes that fertility differences are in part due to different relative wages received by men and women and different prices and income constraints confronting different families. Kuliu (2005) in particular, emphasized the importance of housing. He argues that the size of living spaces is related to overall living and opportunity cost which impacts fertility decisions.

According to Kuliu (2005), the second part of adaptation theory posits that interaction with friends, peers, co-workers and other cultural norms in the new environment shapes individuals beliefs, desire, including parenthood and value of children. However, one may note that this second part of adaptation theory is less immediate than the resource part.

The selection theory posits that migrants are a special group of people with distinct characteristics that account for their fertility behaviour, hence people who migrate are those who would have had fewer children anyway. Ribe and Schultz (1980) maintained that there is a tendency for those who favour small families to migrate to urban areas and for those who favour larger families to relocate to rural areas. With regards to this selection theory it is important to consider who migrates, how and when. The implication of this theory is that migrants from developing countries to developed countries will have lower fertility compared to stayers in the developing countries irrespective of duration of stay by migrants in the developed countries. However, Pesser and Mahler (2003) argued that people come from different social location and have different access to migration opportunities. They argue further that the nature of migration streams change over time, therefore 
a selection bias from 1970 is most likely not applicable in the same way in 2016.

Finally, the disruption theory posits that the experience of migration lowers fertility before and upon arrival into the receiving country because travelling experience disrupts the migrant's life. Such disruption has two faces; firstly, disruption may be due to long separation of husbands and wives. Secondly, disruption to migrate and the subsequent hardship in adapting to a new place motivate couples to postpone having children; the result is that ultimately the couple would have experienced lost in fertility. According to Hervitz (1988), the disruption theory suggests that fertility reduction attributed to disruption is expected to be temporary; the actual fertility level of the couple may still be attained if such disruptive activities are overcome by the couple.

The above four theoretical perspectives of migration places different emphasis on migrant receiving and migrant sending countries. For example, while socializing theory gives more weight to the sending country and adaptation theory giving more weight to the receiving country. Disruption may be placed in both contexts as women may disrupt their fertility by delaying child bearing before migration or continue delaying or start recuperation immediately after migration. Finally, selection theory tends to be more concerned with individuals social locations. Majalantte and Navanecthan (2013) concluded that all four theories may operate at the same time in any given setting.

Although some countries may evolve migration policies to ensure they have a zero net- migration which may act as a balance for any disruption in the fertility rate in their country, however such policies at best are not accurately achievable or sustainable. The reason why such policies remain flowed is mainly due to the fact that migration has a disruptive demographic impact on different countries. Raliu (2005) noted that such demographic impacts includes Population growth, Sex ratio, Age structure, Cohort change and Dependency ratio

In separate studies, Mason (2006 and 2001) and Bloom and Canning (2001) opined that migration impacts on demographic changes have resulted into reduced population growth for migrant sending countries (MSC) and higher growth for migrant receiving countries (MRC); changes in sex ratios according to gender differentials in migration patterns with various direction being possible in both emigration and immigration countries and changes in age structure which mostly results into increased dependency in emigration countries and reduced dependency in immigration countries. This demographic trend is unfavorable to the migrant sending countries (MSC) that are mostly the developing countries and favourable to migrant receiving countries (MRC) who are mostly developed countries. 
All the above mentioned effects of migration with respect to the demographic changes in societies impacts on total fertility rate both for the migrant sending and migrant receiving countries. In most cases it has led to a reduction in total fertility rate of the migrant sending countries (the Sub Sahara African Countries).

The study of the impact of migration on fertility rate of migrant sending countries may have exception, especially in cases where the whole family migrates e.g case of wars, extreme starvation, ethnic cleansing such as the cases of Syria, Afghanistan, Libya, Yemen etc. These cases constitute outliers to this study.

\section{Method}

The study adopted the descriptive analysis method in line with Calmorin (2010), who posited that the descriptive method focus on the present situation (what is), it also describes and interprets conditions and the relationship that exist between them. It takes into cognizance the opinions that are held, process that are on - going, effects that are evident or trends that are developing. Similarly, Ani (2015) noted that the descriptive method is primarily concerned with the present, although it often considers past events and influences as they relate to current conditions. A descriptive analysis is therefore the most adequate analytical method for this analysis.

\section{Procedure}

To effectively determine the expected impact of net-migration on total fertility rate in Sub- Sahara African countries, a simple model relating fertility to net-migration is formulated. The need for a simple model arises because Saleh (2013) noted that, a good theory is the end result of a winnowing process. He noted further that, simple models are preferred both for their philosophical and practical reason, they are easier to put to test again in replication and cross - validation studies, they are less costly to put into practice in predicting and controlling the outcome in the future, and finally, they are easier to understand and appreciate.

The functional form of the model is: FERT $=\mathrm{f}(\mathrm{NMIG}, \mathrm{CLIM}, \mathrm{FST})$

Where:

FERT is Total fertility rate which is defined as the number of children that would be born to a woman if she were to live to the end of her childbearing years and bear children in accordance with current age-specific fertility rates. It serves as the dependent variable.

NMIG is Net-Migration which is the number of immigrants minus the number of emigrants over a period, divided by the person-years lived by the population of the receiving country over that period. It is expressed as net- 
number of migrants per 1,000 populations. It is expected to impact on total fertility rate negatively $(\mathrm{NMIG}<0)$

CLIM is Climate change which is taken as the rate of Carbon dioxide $\left(\mathrm{Co}_{2}\right)$ emission per capital. This includes $\mathrm{Co}_{2}$ produced during consumption of solid, liquid and gas-fuel. It represents $\mathrm{Co}_{2}$ emission from fossil fuels and other manufacturing activities. The variable is expected to impact on total fertility rate negatively (CLIM <0)

FS is Food security which is taken as the level of food deficit is used in the analysis. It indicates how many calories would be needed to lift the undernourished from their status and everything else being constant. The average intensity of food deprivation of the undernourished is estimated as the difference between the average dietary energy requirement and the average dietary energy consumption of the undernourished population (fooddeprived), is multiplied by the number of undernourished to provide an estimate of the total food deficit in the country which is then normalized by the total population. This variable is expected to impact on total fertility rate negatively $(\mathrm{FS}<0)$

The model to be estimated is specified thus:

Fert $_{\mathrm{t}}=\infty_{0}+\infty_{1} \mathrm{NMIG}_{\mathrm{t}}+\infty_{2} \mathrm{CLIM}_{\mathrm{t}}+\infty_{3} \mathrm{FS}_{\mathrm{t}}+\mu_{\mathrm{t}}$

Where:

$\mu$ is the stochastic error term assumed to have zero mean and constant variance.

The parameters to be estimated include $\infty_{0}, \infty_{1}, \infty_{2}$ and $\infty_{3}$,

The data set was estimated using E-views econometric package. Various econometric tests such as unit root test and co-integration were carried out to ensure the data set are stationary and to avoid autocorrelation problem among the variables. To avoid a spurious regression the variables were further tested using Augmented Dickey Fuller and Phillips-Peron test. The data were stationary at first difference. The test of the long -run relationship among variables were equally carried out using Johansen test. The estimated results from the E-view output are presented in table 1.

Table 1. Summary of simple regression analysis of fertility rate $(N=12)$.

\begin{tabular}{cccc} 
Variables & $\beta$ & SE $\beta$ & B \\
\hline Constant & 6.05 & 0.28 & $21.89^{* * *}$ \\
Climate change & 1.49 & 0.67 & $3.94^{*}$ \\
Net-migration & 0.53 & 0.13 & $-3.45^{*}$ \\
Food security & -0.03 & 0.01 & \\
& & & \\
$\mathrm{R}^{2}$ & .87 & & \\
$\mathrm{~F}$ & 17.90 & & \\
\hline
\end{tabular}

${ }^{*} \mathrm{P}<.05 . \quad * * \mathrm{P}<.01$ 
From the analysis, it is discovered that net-migration $(\beta=0.53, P<$ $.05)$, climate change ( $\beta=0.67, P<.05)$ and food security $(~ \beta=0.53, P<.05$ ) were significant precditore to our analysis. The overall model fit is $\mathrm{R}^{2}=0.87$ while the F-value of $17.90(P<.01)$.

\section{Discussion}

The analysis shows that Nigeria's net-migration impacts positively on total fertility rate. However, this result may be due to the prevailing cultural norms in Nigeria where there is preference for male children in Nigeria, a situation which migration activities have not succeeded in changing. This is in line with the findings of Dubta and Dubey (2001). One may also note that data on Nigeria net-migration shows a marginal negative value which indicates that Nigeria attracts migrants from neighbouring countries such as Ghana, Togo, Benin Republic, Cameroun etc with similar culture thereby adequately filling the gaps created by Nigeria migrants.

The individual explanatory variables exhibit different shocks on the Total Fertility Rate. The firs variable which is climate change impacted positively on total fertility rate since an increase in climate change (holding other variable constant) leads to a corresponding increase in total fertility rate . This is against our a priori expectation, however this may be due to the fact that activities of climate change are less visible in developing countries.

The second explanatory variable which is net-migration also impacted positively on total fertility rate because an increase in the net-migration brings about a corresponding increase in the total fertility rate. This implies that netmigration has not necessarily resulted into reduction of total fertility rate in Sub-Sahara Africa countries.

The last explanatory variable in the model which is food security impacted negatively on total fertility rate, an increase in food security situation leads to a decrease in the total fertility rate. This indicates that food security is responsible for the observed decrease in total fertility in Sub-Sahara Africa. This is in line with the findings of Quinn (1997).

The analysis therefore calls to question the current level of food security in Nigeria. This has however, raised an interesting phenomena, showing that food security is an antidote for population control coupled with the cultural orientation of the people within the region that places more preference for male children.

The study empirically analysed the impact of net-migration on total fertility rate in Sub Sahara Africa countries using Nigeria data set, this is in response to the determination of the specific impact of net-migration on total fertility rate in Sub-Sahara Africa countries. The findings of this study will assist policy makers in evolving and managing migration policies that will 
lead to the desired outcome of attaining a fertility rate that will achieve the highest economic growth for the region.

It is recommended that researchers, scholars and policy makers in ubSahara Africa Countries should evolve and adequately manage new migration policies that will encourage a reduced fertility rate that would accelerate a rapid and sustained economic growth by encouraging a balance between emigrants and immigrants. Although other issues such as cultural reorientation e.g. by placing equal preference for male and female children, increased health-care, access to education et cetera should be vigorously pursued as well.

\section{References:}

1. Agbadjanian, V., Yabiku, S.T., \& Can, B.. (2011) Men's migration and Women fertility in rural Mozambique. Demography 48 (3) 1029-1048.

2. Angeles, G., Guikey, D. K., \& Mroz, T. A.. (2005) The Determinants of Fertility in Rural Peru: Programme Effect in the early years of the National Family Planning Programme. Journal of Population Economics. 18: $367-89$

3. Ani, G.T. (2015) Effect of ease of doing Business to Economic growth among Selected Countries in Asia. Asia Pacific journal of multidisciplinary research. 3 (5) 139-145.

4. Beine, M., Docquier, F., and Schiff, M.. (2008). International Migration Transfers of norms and Home Country Fertility. IZAWorking paper No. 3912.

5. Bloom, D., \& Canning, D.. (2001). Cumulative causality, economic growth and the demographic transition. In Pop. Matters ed. N. Birdsall, AC Kelly and SW Sinding 165-197. Oxford: Oxford University Press.

6. Bradatan, C. (2014). When the educated leave the East: Romanian and Hungarian skilled immigration to the USA. Journal of International Migration and Integration. 15 (2) 509-524.

7. Bradatan, C. (2005). Does migration reduce fertility? Evidence from very low fertility country. paa 2005. Princeton.edu.papers.

8. Brocherhoff, M., \& Yang, X.. (1994). Impact of immigration on fertility in Sub-Sahara Africa. Social biology. Spring-summer 41(1-2). $19-43$

9. Caldwell, J. (1982). Theory of fertility Decline. London Academic press.

10. Calmorin L.P. (2007). Research and Statistics with computer. Mandaluyoung City: National Bookstore Manila. 
11. Canglaino, A. (2016). Net-migration as a target for migration Policies: A review and appraisal of the $U K$ experiences. International Migration. Doi.10.1111/1inig 12223.

12. Currias, L. (2000). Population Growth and Health Expenditure. Rev. Bras. Econ. 54(4) http.//dx.doi/10.1590/50034-71402000400002

13. Desta, C. G. (2014). Fertility and Household Economic Wellbeing in Ethiopia, A Case Study in the Amhara Region (unpublished doctoral dissertation). Addis Ababa University, Addis Ababa.

14. Dupta, N. D. \& Dubey, A. (2011). Poverty and Fertility. An Instrument variable analysis on India micro Data. (Working paper No 03/11). Aurhus University. Department of Economics.

15. Ebank, G.E., George, P.M., \& Nobbe, C. E.. (1975). Emigration and fertility Decline: The case of Barbados: Demography 12 (3) 431-445.

16. Fargues, P. (2007). The demographic benefit of International migration; a hypothesis and its application to Middle Eastern and North African Countries in Ozlen C and M. Schys (ed). International migration economic development and Policy. World Bank and Palgrave Macmillan: Washington D. C.

17. Genereux, A. (2007). A review of migration and fertility theory through the lens of Africa immigrant fertility in France: MPIDR working paper WP 2007-2008.

18. Goldstein, S. (1996). Facets of Redistribution: Research challenges Opportunities. Demography. 13 (1) 423-443.

19. Hamear, T., \& Tomas, K.. (1997). Why Do people Go or Stay? In T Hammar and all (ed) International Migration, Immobility and Development Oxford: Berg.

20. Hervitz, H.M. (1985). Selectivity, Adaptation or Disruption? A Comparism of Alternative Hypothesis on the effect of Fertility: The case of Brazil: International Migration Review 19 (2) 293-317.

21. Jensen, E.R., \& Ahiburge, A. D.. (2004). Does migration reduce fertility: evidence from the Philippines. Population Studies. 58 (2) 219231.

22. Kaln, J.R. (1994). Immigrant and native fertility during the 1980s: adaptations for the future. International Migration Review. 28:501519.

23. Kalwa, A. (2010). The Impact of Family Policy Expenditure on Fertility in Western Europe. Demography. 47(2) 503 - 519

24. Kulu, H. (2005). Migration and Fertility: Competing Hypothesis Reexamined, European Journal of Population. 21, 51-87.

25. Law, A. M., \& Kelton ,W.D.. (1982). Simulation modelling and Analysis. New York, NY: McGraw-Hill. 
26. Lindstrom, D.P., \& Saucedo, S.G.. (2002). The short and Long-term effect of U.S Migration Experience on Mexican Women fertility. Social Force. 80(4) $1341-1368$.

27. Madhavan, S. (2001). Female relationship and demographic outcomes in SSA. Sociological Forum. 16 (3) 503-527.

28. Madhavan, S. (2001). Female Relationship and Demographic Outcomes in Sub-Sahara Africa. Sociological Forum. (16) 3. 503 527

29. Majalantte, R.G., \& Navanecthan, K.. (2013). Migration and Fertility: A review of theories and evidences. Journal of Global Economics. Vol. 1 (1) 1-3.

30. Marphy, M. (2016). The effect of Long-term migration dynamics on population structure in England and Wales and Scotland. A Journal of demography. 70 (2). 149-162.

31. Mason, A. (2001). Population and Economic growth in East Asia. In population change and Economic Development in East Asia; challenges met, Opportunities Seized. A Mason (ed). 1-30 Stanford, CA: Stanford University Press.

32. Mason, A. (2001). Population, aging and demographic dividends; The time to Act is now. Asia Pacific Population Journal. 21 (3) 7-16.

33. McNrcoll, G. (1970). Population and Poverty: A Review and Restatement. Policy Research division working paper 105. Ney York, NY: Population Journal

34. OECD. (2017). Fertility Rates (indicator). doi: 101787/8272F601-en (Accessed on $24^{\text {th }}$ August 2017 http/data.oecd.org/pop/fertility-rates htm.

35. Quinn, D. (1997). The story of B. Bantam Books New York. New York.

36. Raliu, J. L. (2006). Female deficit and the marriage market in Korea. Demographic Research. (15) pg. 51-60.

37. Raliu, J.L. (2008). Population, migration and development in Asia with special emphasis on the South Pacific; The impact of migration on population and the MDGs. UN/POP/EGM/2008/2 20-21. September, 2008.

38. Rube, H., \& Schultz, T.P.. (1980). Migrant and Native fertility at destination in Colombia: Are Migrants selected According to their Reproductive Preferences? Center Discussion Paper, No. 355.

39. Saleh, A. S. E. (2013). Assessing the impact of doing business indicators on the GDP growth in Egypt. International Journal of research in Social Science. 3 (4) 32-52.

40. Schultz, T. P. (2005). Fertility and Income. Centre discussion paper No 925. Economic Growth Centre. Yale University http.//www.econ.yale.edu/-egcenter/research.htm 
41. Singlay, S., \& Landale, N.. (1998). Incorporating origin and process in Migration-fertility Framework: The case of Puerto Rican Women. Social Force. 76 (4) 1437-70.

42. Slebos, J. (2003). Low fertility rates in OECD Countries; Facts and Policy responses. OECD Social, Employment migration. Working Papers 15.

43. Stephen, E.H., \& Bean, F.D.. (1992). Assimilation disruption and the fertility of Mexican-origin women in the $U S$. International Migration Review 26, 67-88.

44. Stephens, J., Newman, K., \& Mayhew, S.. (2010). Population dynamics and climate change: What are the links? Journal of Public health. 32(2) 150-1556.

45. Zhai, B.N., Bouvier, F.L.. \& Poston, L. D.. (1995) .Zero Netinternational Migration: What does it really mean? Retrieved on $12^{\text {th }}$ Nov. 2017 from https://cis.org/zero-net-iternational-migration. what does it really mean? 